\title{
Eating Alone and Cognitive Decline in Korean Older Adults: A 3-Year Prospective Study
}

\author{
Hye-Mi Noh ${ }^{1}$, Junhee $\mathrm{Han}^{2}$, Yong Kyun Roh ${ }^{3}$, Hong Ji Song ${ }^{1}$ \\ ${ }^{1}$ Department of Family Medicine, Hallym University Sacred Heart Hospital, Hallym University College of Medicine, Anyang, Korea \\ ${ }^{2}$ Department of Statistics and Institute of Statistics, Hallym University, Chuncheon, Korea \\ ${ }^{3}$ Department of Family Medicine, Hallym University Kangnam Sacred Heart Hospital, Seoul, Korea
}

Corresponding Author:

Hong Ji Song, $\mathrm{MD}, \mathrm{PhD}$

Department of Family Medicine,

Hallym University Sacred Heart

Hospital, Hallym University College of

Medicine, Anyang 14068, Korea

E-mail: hongji@hallym.ac.kr

ORCID:

https://orcid.org/0000-0002-3563-9504

Junhee Han, $\mathrm{PhD}$

Department of Statistics and Institute

of Statistics, Hallym University, 1

Hallimdaehak-gil, Chuncheon 24252,

Korea

E-mail: hanjh@hallym.ac.kr

ORCID:

https://orcid.org/0000-0001-5736-8752

Received: December 9, 2020

Revised: January 25, 2021

Accepted: January 30, 2021
Background: Eating alone is a critical factor in nutritional risk screening among older adults. We investigated whether changes in eating status (eating alone or with others) in late-life affected cognitive decline in community-dwelling older adults. Methods: We used data from the Survey of the Living Conditions and Welfare Needs of Korean Older Persons. Nutritional risk, including eating status, was assessed using seven questions from the Nutrition Screening Initiative checklist, and cognitive function was measured using the Mini-Mental State Examination (MMSE). On the basis of changes in eating status between baseline (2008) and the 3-year follow-up (2011), the subjects were divided into four groups: group 1 (eating with others at both surveys), group 2 (eating alone in 2008 and eating with others in 2011), group 3 (eating with others in 2008 and eating alone in 2011), and group 4 (eating alone at both surveys). Generalized linear models were used to compare the changes in MMSE scores over the 3-year period among the four groups. Results: Among older women, group 2 had the least decline in MMSE scores $(-0.55 \pm 0.46)$, whereas group 3 had the greatest decline $(-1.76 \pm 0.37)(p=0.034)$. We observed no difference in the change in MMSE scores among the four eating groups in older men. Conclusion: Deprivation of mealtime partners in late life showed significant cognitive decline compared with gaining mealtime partners. Eating alone may be a risk factor for cognitive impairment; thus, meal programs reinforcing social integration might help preserve cognitive function.

Key Words: Aged, Cognition, Eating

\section{INTRODUCTION}

Cognitive impairment and malnutrition are common health concerns in older adults. ${ }^{1,2)}$ Numerous studies have reported associations between nutritional factors and cognitive function. ${ }^{3)}$ For instance, a Japanese prospective study reported that poor nutritional status increased the risk of cognitive decline, ${ }^{4)}$ whereas a multinational cohort study revealed that a higher-quality diet reduced the risk of cognitive decline. ${ }^{5)}$ Dining is an essential activity in daily living. Eating alone or with others is a critical factor for the screening of nutritional risk in older adults and is included in the Nutrition Screening Initiative (NSI) checklist. ${ }^{6}$ Eating with others can en- hance food and calorie intake, leading to social interaction with other people during mealtimes. ${ }^{7)}$ However, older adults who eat alone tend to skip meals and have less food diversity. ${ }^{8)}$ Therefore, "eating alone" reflects both nutritional status and social life among older adults. Social frailty, which refers to a lack of social activities and social resources, is an important issue in older adults and is associated with a risk of cognitive impairment and dementia. ${ }^{9)}$ Thus, more extensive social networks may help prevent dementia. ${ }^{10}$

However, few studies have explored the influence of eating alone on cognitive function in older adults. A prospective Taiwanese study reported a combined effect of nutritional status and eating alone on cognitive function, wherein older women with poor nu- 
tritional status who ate alone showed a greater cognitive decline than did women with normal nutritional status who ate with others. ${ }^{11)}$ The results of a recent Japanese cross-sectional study suggested an association between eating alone (despite living with family) and frailty, mainly impaired memory domains, in older women. $^{12)}$

On the basis of existing evidence, we hypothesized that "eating alone" was a modifiable risk factor for cognitive impairment in older adults and investigated the effects of changes in eating status (eating alone or with others) in late-life over a 3-year period on cognitive decline among community-dwelling Korean older adults.

\section{MATERIALS AND METHODS}

\section{Study Population}

Our study used data from the 2008 and 2011 Surveys of Living Conditions and Welfare Needs of Koran Older Persons. The surveys are conducted by the Korea Institute for Health and Social Affairs and have been performed at 3-year intervals on a representative sample of community-dwelling Korean older adults (aged $\geq 60$ years) since 2008 . The surveys include health-related information such as a medical history of chronic diseases and cancers, functional disabilities, nutritional status, Geriatric Depression Scale (GDS) score, cognitive function, health behaviors, body weight, and height. In this study, we included 9,459 subjects who had participated in both the first- and second-wave surveys (2008 and 2011). We excluded subjects who were aged $<65$ years $(n=1,328)$; were frail, disabled, or had cancer $(n=1,275)$; had dementia or cognitive impairment $(n=1,744)$; or were missing data on nutritional status or cognitive function $(\mathrm{n}=966)$. Finally, we included 4,146 subjects in this study. All subjects provided informed consent before participation in the study, either by themselves or, in cases of decision-impaired adults, through a legally authorized representative. This study was approved by the Institutional Review Board of Hallym University Sacred Heart Hospital (No. 2018-04-028).

\section{Measurements}

\section{Nutritional risk and eating status}

Nutritional risk was assessed using a questionnaire consisting of seven questions (on disease; eating less than two meals per day; eating few fruits, vegetables, and dairy products; tooth loss/mouth pain; economic hardship; reduced social contact; and involuntary weight loss/gain) from the NSI checklist. ${ }^{6}$ The total score ranged from 0 to 7, with higher scores indicating higher nutritional risk.
The nutritional risk was divided into two categories on the basis of this score: "good" (0-2 points) and "not good" (3-7 points). To assess eating status, we used responses to the question, "Do you often eat alone?" among the seven questions. Eating status was assessed at baseline (2008) and at the 3-year follow-up (2011). On the basis of changes in eating status over a 3-year period, the subjects were divided into four groups: group $1(n=2,777$, eating with others in both 2008 and 2011), group $2(n=237$, eating alone in 2008 and eating with others in 2011), group $3(n=586$, eating with others in 2008 and eating alone in 2011), and group 4 $(n=787$, eating alone in both 2008 and 2011).

\section{Cognitive function}

At baseline (2008) and the follow-up survey (2011), cognitive function was evaluated using the Korean version of the Mini-Mental Status Examination (MMSE-KC). The MMSE-KC uses the Korean language and has been standardized, with scores ranging from 0 to 30. Trained researchers administered the MMSE-KC in a separate space where the subjects would not be disturbed for approximately 10 minutes. Cognitive impairment was defined as an MMSE-KC score of < 1.5 standard deviations from the age-, sex-, and education-adjusted norm for older Koreans. ${ }^{13)}$ To assess cognitive change over a 3-year period, we calculated the difference of MMSE-KC between at baseline and at follow-up survey.

\section{Covariates}

Participant demographic information, including age, sex, educational level, household income, marital status, and living status were collected. Smoking status was classified as never, ex-, or current smoker. Alcohol drinking status was classified as non-high-risk and high-risk drinkers. High-risk alcohol consumption was defined as drinking alcohol $\geq 2$ days/week and $\geq 7$ (men) or $\geq 5$ (women) standard-sized drinks/drinking day. Physical activity was classified as adequate if $>150 \mathrm{~min} /$ week of exercise was reported. ${ }^{14)}$ Disease history (hypertension, diabetes mellitus, dyslipidemia, and depression) and the number of medications were also assessed. The short version of the GDS contains 15 questions, which were translated into Korean. The GDS scores range from 0 to 15 , with scores $\geq 8$ indicating depression. ${ }^{15)}$ Physical performance was assessed by asking patients whether they could run around a playground (400 $\mathrm{m})$, walk around a playground (400 m), climb 10 stairs without rest, bend their body, squat, sit with bent knees, and stretch their arms to place something above their heads. The possible answers were "can do it easily" (4 points), "can do it but slightly difficult" (3 points), "can do it but very difficult" ( 2 points), and "cannot do it" (1 point). The scores were summed and graphed on a 100-point scale. We divided the subjects into tertiles according to their physi- 
cal performance scores.

\section{Statistical analysis}

Considering for the complex sampling design of the Survey of Living Conditions and Welfare Needs of Korean Older Persons, we used sampling weights in all the analyses. For baseline characteristics, we calculated the means with standard deviations or frequencies (percentages). The assumption of normality of the data was evaluated using Shapiro-Wilk tests, with p-values $>0.05$ indicating that the observed distribution of a variable was not significantly different from the normal distribution. The MMSE-KC was log-transformed to fit a normal distribution. We used analysis of variance tests to compare continuous variables and chi-square tests to compare categorical variables among the four eating status groups. We used generalized linear models (GLM) to compare the changes in cognitive function among the four eating groups after adjusting for potential confounding factors. Age and sex were adjusted in Model 1, and household income, marital status, and living status were adjusted in Model 2 in addition to age and sex. In Model 3, health behaviors, physical performance, body mass index, and GDS score were added to the variables in Model 2, and finally, in Model 4, comorbidities and the number of medications were added to the variables in Model 3 as adjusted variables. All tests were two-sided, with a significance level set at $\mathrm{p}<0.05$. All analyses were performed using SAS software version 9.3 (SAS Institute, Cary, NC, USA).

\section{RESULTS}

Table 1 shows the baseline characteristics of the four groups. The

Table 1. Baseline characteristics of the study participants according to eating status

\begin{tabular}{|c|c|c|c|c|c|}
\hline & Group $1(n=2,777)$ & Group $2(n=237)$ & Group $3(n=586)$ & Group $4(n=787)$ & p-value \\
\hline Age (y) & $71.1 \pm 5.4$ & $71.5 \pm 5$ & $72.4 \pm 5.6$ & $73.7 \pm 5.3$ & $<0.0001$ \\
\hline Sex & & & & & $<0.0001$ \\
\hline Male & $1,442(51.9)$ & $83(35.2)$ & $157(26.9)$ & $89(11.3)$ & \\
\hline Female & $1,336(48.1)$ & $154(64.8)$ & $428(73.1)$ & $698(88.7)$ & \\
\hline Educational attainment & & & & & $<0.0001$ \\
\hline Less than middle school & $1,765(63.6)$ & $168(70.8)$ & $435(74.2)$ & $658(83.7)$ & \\
\hline Middle-high school and above & $1,012(36.4)$ & $69(29.2)$ & $151(25.8)$ & $129(16.3)$ & \\
\hline Household net worth & & & & & $<0.0001$ \\
\hline 1st quintile & $259(9.3)$ & $35(14.8)$ & $119(20.4)$ & $348(44.2)$ & \\
\hline 2nd quintile & $524(18.9)$ & $61(25.5)$ & $134(22.9)$ & $206(26.2)$ & \\
\hline 3rd quintile & $676(24.3)$ & $58(24.3)$ & $127(21.8)$ & $112(14.3)$ & \\
\hline 4th quintile & $636(22.9)$ & $41(17.3)$ & $98(16.6)$ & $75(9.5)$ & \\
\hline 5th quintile & $683(24.6)$ & $43(18.1)$ & $107(18.3)$ & $45(5.8)$ & \\
\hline Marital status & & & & & $<0.0001$ \\
\hline Single/widowed/divorced & $304(10.9)$ & $102(43.0)$ & $301(51.3)$ & $738(93.8)$ & \\
\hline Married & $2,473(89.1)$ & $135(57.0)$ & $285(48.7)$ & $49(6.2)$ & \\
\hline Living status & & & & & $<0.0001$ \\
\hline Living with others & $1,890(98.7)$ & $107(67.9)$ & $253(63.78)$ & $44(6.9)$ & \\
\hline Living alone & $25(1.3)$ & $51(32.1)$ & $144(36.22)$ & $592(93.1)$ & \\
\hline Smoking & & & & & $<0.0001$ \\
\hline Never smoker & $1,666(60.0)$ & $161(68.0)$ & $449(76.7)$ & $649(82.5)$ & \\
\hline Ex-smoker & $673(24.2)$ & $48(20.4)$ & $80(13.7)$ & $64(8.2)$ & \\
\hline Current smoker & $439(15.8)$ & $28(11.6)$ & $57(9.6)$ & $74(9.3)$ & \\
\hline Alcohol & & & & & $<0.0001$ \\
\hline Non-high-risk drinker & $2,524(90.9)$ & $220(93.0)$ & $556(95.0)$ & $761(96.8)$ & \\
\hline High risk drinker & $254(9.1)$ & $17(7.0)$ & $30(5.0)$ & $26(3.2)$ & \\
\hline Physical exercise & & & & & $<0.0001$ \\
\hline None & $2,285(82.3)$ & $210(88.8)$ & $521(88.9)$ & $720(91.5)$ & \\
\hline Adequate exercise & $492(17.7)$ & $26(11.2)$ & $65(11.1)$ & $67(8.5)$ & \\
\hline Nutritional risk & & & & & $<0.0001$ \\
\hline
\end{tabular}


Table 1. Continued

\begin{tabular}{|c|c|c|c|c|c|}
\hline & Group $1(n=2,777)$ & Group $2(n=237)$ & Group $3(n=586)$ & Group $4(n=787)$ & $\mathrm{p}$-value \\
\hline Good & $1,920(69.1)$ & $53(22.6)$ & $366(62.5)$ & $131(16.6)$ & \\
\hline Not good & $857(30.9)$ & $183(77.4)$ & $220(37.5)$ & $656(83.4)$ & \\
\hline Physical performance & & & & & $<0.0001$ \\
\hline 1st tertile & $600(21.7)$ & $75(31.9)$ & $198(34.1)$ & $350(45.1)$ & \\
\hline 2nd tertile & $926(33.6)$ & $86(36.4)$ & $216(37.1)$ & $281(36.3)$ & \\
\hline 3rd tertile & $1,231(44.7)$ & $74(31.7)$ & $168(28.8)$ & $144(18.6)$ & \\
\hline BMI categories & & & & & $<0.0001$ \\
\hline Underweight & $81(3.0)$ & $7(2.9)$ & $32(5.8)$ & $32(4.3)$ & \\
\hline Normal & $1,030(38.4)$ & $90(38.6)$ & $206(37.0)$ & $284(38.5)$ & \\
\hline Overweight & $773(28.9)$ & $53(22.7)$ & $123(22.1)$ & $146(19.7)$ & \\
\hline Obesity & $795(29.7)$ & $84(35.8)$ & $196(35.1)$ & $277(37.5)$ & \\
\hline Mean BMI $\left(\mathrm{kg} / \mathrm{m}^{2}\right)$ & $23.7 \pm 3.2$ & $24.2 \pm 3.6$ & $23.7 \pm 3.5$ & $23.9 \pm 3.3$ & 0.068 \\
\hline GDS & & & & & $<0.0001$ \\
\hline$<8$ & $2,360(85.8)$ & $165(69.8)$ & $437(75.5)$ & $473(60.2)$ & \\
\hline$\geq 8$ & $391(14.2)$ & $72(30.2)$ & $142(24.5)$ & $313(39.8)$ & \\
\hline \multicolumn{6}{|l|}{ Comorbidities } \\
\hline Hypertension & $1,214(43.7)$ & $142(60.0)$ & $305(52.1)$ & $414(52.6)$ & 0.053 \\
\hline Diabetes mellitus & $408(14.7)$ & $49(20.7)$ & $85(14.5)$ & $132(16.7)$ & $<0.0001$ \\
\hline Dyslipidemia & $147(5.3)$ & $21(8.8)$ & $31(5.2)$ & $34(4.3)$ & 0.056 \\
\hline Depression & $20(0.7)$ & $3(1.3)$ & $3(0.6)$ & $24(3.1)$ & $<0.0001$ \\
\hline Numbers of medications & $1.8 \pm 1.2$ & $2.0 \pm 1.2$ & $1.9 \pm 1.3$ & $2.1 \pm 1.1$ & $<0.0001$ \\
\hline MMSE-KC in 2008 & $25.7 \pm 3.4$ & $25.3 \pm 3.8$ & $24.5 \pm 3.5$ & $23.4 \pm 3.6$ & $<0.0001$ \\
\hline MMSE-KC in 2011 & $24.8 \pm 4.3$ & $24.1 \pm 4.7$ & $23 \pm 4.4$ & $22.3 \pm 4.2$ & $<0.0001$ \\
\hline Change in MMSE-KC & $-0.9 \pm 3.7$ & $-1.2 \pm 4.2$ & $-1.5 \pm 3.8$ & $-1.1 \pm 3.6$ & 0.010 \\
\hline Cognitive impairment in 2011 & & & & & 0.439 \\
\hline No & $2,333(84.0)$ & $204(86.2)$ & $490(83.6)$ & $677(86.0)$ & \\
\hline Yes & $444(16.0)$ & $33(13.8)$ & $96(16.4)$ & $110(14.0)$ & \\
\hline
\end{tabular}

Values are presented as mean \pm standard deviation or frequencies (\%).

The subjects were divided into four groups: group 1 (eating with others in both 2008 and 2011), group 2 (eating alone in 2008 and eating with others in 2011), group 3 (eating with others in 2008 and eating alone in 2011), and group 4 (eating alone in both 2008 and 2011).

BMI, body mass index; GDS, Geriatric Depression Scale; MMSE-KC, Mini-Mental State Examination (Korean version).

weighted number of total study population was 4,387. Group 1 (eating with others in both 2008 and 2011) had the lowest mean age (71.1 \pm 5.4 years) and percentage of women $(48.1 \%)$ but the highest education level and household income. This group also had the highest percentages of subjects who were married (89.1\%) and lived with others (98.7\%). Conversely, group 4 (eating alone in both 2008 and 2011) had the highest mean age (73.7 \pm 5.3 years) and percentage of women (88.7\%). In contrast, this group had the lowest education level, household income, and percentages of subjects who were married (6.2\%) and living with others (6.9\%). Regarding health behaviors, group 1 had the highest percentages of current smokers (15.8\%), high-risk drinking (9.1\%), adequate exercise (17.7\%), good nutritional status $(69.1 \%)$, and good physical performance (44.7\%) but the lowest percentage of a higher GDS score $(\geq 8,14.2 \%)$. Group 4 had the lowest percentages of current smokers (9.3\%), high-risk drinking (3.2\%), ade- quate exercise (8.5\%), good nutritional status (16.6\%), and good physical performance (18.6\%) and the highest percentage of higher GDS scores ( $\geq 8,39.8 \%)$.

Group 1 had the highest MMSE-KC score at both baseline and the 3-year follow-up ( $25.7 \pm 3.4$, and $24.8 \pm 4.3$, respectively), whereas group 4 had the lowest scores at both survey $(23.4 \pm 3.6$, and $22.3 \pm 4.2$, respectively). At the 3-year follow-up, 683 subjects (16.5\%) showed cognitive impairment. There was no significant difference in the prevalence of cognitive impairment among the four groups.

Table 2 shows the MMSE-KC scores at the follow-up survey for the four eating groups after adjusting for potential confounding factors. Group 2 (eating alone in 2008 and eating with others in 2011) had the highest MMSE-KC score, whereas group 3 (eating with others in 2008 and eating alone in 2011) had the lowest MMSE-KC score. When we performed a sex-stratified analysis, 
Table 2. Comparisons of MMSE-KC scores at the follow-up survey among four eating groups

\begin{tabular}{|c|c|c|c|c|c|}
\hline \multicolumn{2}{|c|}{ Eating status } & \multirow{2}{*}{$\begin{array}{c}\text { Model } 1 \\
24.40 \pm 0.08\end{array}$} & \multirow{2}{*}{$\begin{array}{c}\text { Model } 2 \\
24.72 \pm 0.13\end{array}$} & \multirow{2}{*}{$\begin{array}{c}\text { Model 3 } \\
23.94 \pm 0.16\end{array}$} & \multirow{2}{*}{$\begin{array}{r}\text { Model } 4 \\
23.75 \pm 0.19\end{array}$} \\
\hline Total & Group 1 & & & & \\
\hline & Group 2 & $24.19 \pm 0.27$ & $25.13 \pm 0.30$ & $24.67 \pm 0.30$ & $24.41 \pm 0.34$ \\
\hline & Group 3 & $23.34 \pm 0.17$ & $23.85 \pm 0.19$ & $23.42 \pm 0.22$ & $23.28 \pm 0.24$ \\
\hline & Group 4 & $23.07 \pm 0.15$ & $23.71 \pm 0.23$ & $23.54 \pm 0.24$ & $23.61 \pm 0.26$ \\
\hline & p-value & $<0.0001$ & $<0.0001$ & 0.002 & 0.026 \\
\hline \multirow[t]{5}{*}{ Male } & Group 1 & $26.15 \pm 0.09$ & $26.04 \pm 0.12$ & $25.36 \pm 0.16$ & $25.17 \pm 0.19$ \\
\hline & Group 2 & $25.56 \pm 0.37$ & $25.89 \pm 0.42$ & $25.18 \pm 0.41$ & $24.88 \pm 0.47$ \\
\hline & Group 3 & $25.34 \pm 0.27$ & $25.53 \pm 0.32$ & $25.04 \pm 0.33$ & $25.18 \pm 0.39$ \\
\hline & Group 4 & $25.40 \pm 0.36$ & $25.78 \pm 0.54$ & $25.29 \pm 0.52$ & $26.12 \pm 0.59$ \\
\hline & p-value & 0.005 & 0.504 & 0.786 & 0.393 \\
\hline \multirow[t]{5}{*}{ Female } & Group 1 & $23.33 \pm 0.12$ & $23.98 \pm 0.23$ & $21.87 \pm 0.37$ & $21.85 \pm 0.39$ \\
\hline & Group 2 & $23.30 \pm 0.36$ & $24.63 \pm 0.42$ & $23.30 \pm 0.47$ & $23.17 \pm 0.50$ \\
\hline & Group 3 & $22.14 \pm 0.22$ & $22.87 \pm 0.26$ & $21.30 \pm 0.38$ & $21.22 \pm 0.39$ \\
\hline & Group 4 & $21.89 \pm 0.17$ & $22.75 \pm 0.25$ & $21.59 \pm 0.35$ & $21.63 \pm 0.37$ \\
\hline & p-value & $<0.0001$ & $<0.0001$ & 0.0004 & 0.001 \\
\hline
\end{tabular}

Values are presented as mean \pm standard deviation or frequencies (\%).

The subjects were divided into four groups: group 1 (eating with others in both 2008 and 2011), group 2 (eating alone in 2008 and eating with others in 2011), group 3 (eating with others in 2008 and eating alone in 2011), and group 4 (eating alone in both 2008 and 2011). Model 1 was adjusted for age and sex; Model 2 was additionally adjusted for and household income, marital status, and living status; Model 3 was additionally adjusted for health behaviors, physical performance, body mass index, and Geriatric Depression Scale score; and Model 4 was additionally adjusted for comorbidities and the number of medications. MMSE-KC, Mini-Mental State Examination (Korean version).

the difference was significant only in women and not in men. In women, group 2 had the highest MMSE-KC score (23.2 \pm 0.5$)$, whereas group 3 had the lowest MMSE-KC score (21.2 \pm 0.4$)$ $(\mathrm{p}=0.014)$.

Table 3 shows the comparisons of cognitive changes over a 3 -year period among the four eating groups. In the total study population, there was no difference in cognitive changes among the groups. However, among women, group 2 had the least change in MMSE-KC scores over the 3-year follow-up (-0.55 \pm 0.46$)$, whereas group 3 had the greatest change in MMSE-KC scores $(-1.76 \pm 0.37)$ after adjusting for potential confounding factors $(\mathrm{p}=0.034)$. When we divided the subjects into two groups by age ( $<75$ and $\geq 75$ years), the difference was more prominent in subjects aged $<75$ years $(-0.59 \pm 0.36$ in group 2 and $-1.4 \pm 0.29$ in group 3$)$, which was marginally significant $(p=0.051)$.

\section{DISCUSSION}

The results of this large representative study showed that a change in eating status in late-life over a 3-year period affected cognitive decline in Korean older adults. Older women who ate alone at baseline but who ate with others at the follow-up survey had the least cognitive decline. In contrast, older women who ate with others at baseline but ate alone at the follow-up survey had the greatest cognitive decline. Deprivation of mealtime partners in late life caused greater cognitive decline than did gaining mealtime partners among older women. Thus, "eating alone" may be a modifiable risk factor for cognitive impairment in older adults.

These findings are consistent with those of previous studies. The results of a Japanese cross-sectional study suggested an association between eating alone, despite living with family, and impaired memory domains of frailty in older women. ${ }^{12)}$ A prospective study in Taiwan reported a negative association between a combination of poor nutritional status and eating alone with cognitive function in older women. ${ }^{11)}$ However, these previous studies examined the combined effects of eating alone and nutritional status or living status on cognitive function. Unlike previous studies, we found that eating alone was independently associated with cognitive decline in older adults after adjusting for nutritional risk or living status.

There are several possible mechanisms by which eating status affects cognitive function in older adults. First, commensality might provide companionship, social support, and social integration. ${ }^{16)}$ However, older adults who eat alone lack opportunities for social interactions or exchange of information with other people during mealtimes. Conversation with others is cognitively stimulating and requires linguistic ability, attention, working memory, executive functions, and social cognition to understand others' feelings and intentions. ${ }^{17)}$ Conversation while eating is a highly developed function that is confined to humans. Interestingly, in the present study, 
Table 3. Comparisons of the changes of MMSE-KC scores over the 3-year study period among the four eating groups

\begin{tabular}{|c|c|c|c|c|c|}
\hline \multicolumn{2}{|c|}{ Eating status } & \multirow{2}{*}{$\begin{array}{c}\text { Model } 1 \\
-1.02 \pm 0.07\end{array}$} & \multirow{2}{*}{$\begin{array}{r}\text { Model } 2 \\
-0.89 \pm 0.12\end{array}$} & \multirow{2}{*}{$\begin{array}{c}\text { Model } 3 \\
-0.89 \pm 0.16\end{array}$} & \multirow{2}{*}{$\begin{array}{r}\text { Model } 4 \\
-0.94 \pm 0.18\end{array}$} \\
\hline Total & Group 1 & & & & \\
\hline & Group 2 & $-1.26 \pm 0.24$ & $-0.74 \pm 0.28$ & $-0.85 \pm 0.29$ & $-0.69 \pm 0.32$ \\
\hline & Group 3 & $-1.44 \pm 0.15$ & $-1.21 \pm 0.18$ & $-1.22 \pm 0.21$ & $-1.14 \pm 0.23$ \\
\hline & Group 4 & $-0.97 \pm 0.14$ & $-1.22 \pm 0.21$ & $-1.39 \pm 0.23$ & $-1.17 \pm 0.25$ \\
\hline & p-value & 0.060 & 0.330 & 0.259 & 0.566 \\
\hline \multirow[t]{5}{*}{ Male } & Group 1 & $-0.91 \pm 0.09$ & $-0.84 \pm 0.11$ & $-1.21 \pm 0.17$ & $-1.26 \pm 0.19$ \\
\hline & Group 2 & $-1.79 \pm 0.35$ & $-1.32 \pm 0.41$ & $-1.90 \pm 0.43$ & $-1.57 \pm 0.47$ \\
\hline & Group 3 & $-0.99 \pm 0.26$ & $-0.72 \pm 0.31$ & $-0.88 \pm 0.33$ & $-0.57 \pm 0.40$ \\
\hline & Group 4 & $-1.09 \pm 0.34$ & $-0.94 \pm 0.53$ & $-1.44 \pm 0.53$ & $-0.62 \pm 0.61$ \\
\hline & p-value & 0.115 & 0.684 & 0.252 & 0.218 \\
\hline \multirow[t]{5}{*}{ Female } & Group 1 & $-1.09 \pm 0.11$ & $-0.92 \pm 0.21$ & $-1.20 \pm 0.35$ & $-1.14 \pm 0.37$ \\
\hline & Group 2 & $-0.99 \pm 0.32$ & $-0.40 \pm 0.38$ & $-0.62 \pm 0.45$ & $-0.55 \pm 0.46$ \\
\hline & Group 3 & $-1.62 \pm 0.19$ & $-1.48 \pm 0.23$ & $-1.90 \pm 0.36$ & $-1.76 \pm 0.37$ \\
\hline & Group 4 & $-0.99 \pm 0.15$ & $-1.35 \pm 0.22$ & $-1.84 \pm 0.34$ & $-1.71 \pm 0.35$ \\
\hline & p-value & 0.049 & 0.059 & 0.012 & 0.034 \\
\hline \multirow[t]{5}{*}{ Age $<75 y$} & Group 1 & $-0.77 \pm 0.08$ & $-0.57 \pm 0.12$ & $-0.63 \pm 0.18$ & $-0.65 \pm 0.21$ \\
\hline & Group 2 & $-0.96 \pm 0.26$ & $-0.53 \pm 0.30$ & $-0.77 \pm 0.33$ & $-0.59 \pm 0.36$ \\
\hline & Group 3 & $-1.44 \pm 0.18$ & $-1.46 \pm 0.21$ & $-1.46 \pm 0.25$ & $-1.40 \pm 0.29$ \\
\hline & Group 4 & $-0.89 \pm 0.17$ & $-1.37 \pm 0.26$ & $-1.58 \pm 0.29$ & $-1.16 \pm 0.31$ \\
\hline & p-value & 0.007 & 0.002 & 0.004 & 0.051 \\
\hline \multirow[t]{5}{*}{ Age $\geq 75 y$} & Group 1 & $-1.58 \pm 0.17$ & $-2.00 \pm 0.35$ & $-1.75 \pm 0.40$ & $-1.61 \pm 0.43$ \\
\hline & Group 2 & $-2.04 \pm 0.54$ & $-1.54 \pm 0.67$ & $-1.38 \pm 0.70$ & $-1.20 \pm 0.73$ \\
\hline & Group 3 & $-1.44 \pm 0.30$ & $-0.82 \pm 0.35$ & $-0.87 \pm 0.39$ & $-0.80 \pm 0.42$ \\
\hline & Group 4 & $-1.26 \pm 0.23$ & $-0.77 \pm 0.36$ & $-0.77 \pm 0.41$ & $-1.05 \pm 0.44$ \\
\hline & p-value & 0.523 & 0.066 & 0.279 & 0.445 \\
\hline
\end{tabular}

Values are presented as mean \pm standard deviation or frequencies (\%).

The subjects were divided into four groups: group 1 (eating with others in both 2008 and 2011), group 2 (eating alone in 2008 and eating with others in 2011), group 3 (eating with others in 2008 and eating alone in 2011), and group 4 (eating alone in both 2008 and 2011). Model 1 was adjusted for age and sex; Model 2 was additionally adjusted for and household income, marital status, and living status; Model 3 was additionally adjusted for health behaviors, physical performance, body mass index, and Geriatric Depression Scale score; and Model 4 was additionally adjusted for comorbidities and the number of medications. MMSE-KC, Mini-Mental State Examination (Korean version).

we observed sex differences in the impact of eating alone on cognitive decline, with significant results observed only among women. Women tend to contribute more utterances to conversations than men at family dinner time. ${ }^{18)}$ Further studies are needed to elucidate how the quantity and quality of conversations during mealtimes affect cognitive function in older adults. Second, poor social networks and social activities may increase the risk of dementia. ${ }^{19,20)}$ The results of a randomized controlled trial suggested that a multicomponent intervention including social activities improved cognitive function in older adults with mild cognitive impairment. $^{21)}$ A 6-week randomized controlled trial concluded that web-based conversational interactions improved cognitive function in older adults without dementia. ${ }^{22)}$ Mealtime conversation is expected to decrease in frequency during the current outbreak of coronavirus disease 2019 (COVID-19), which may accelerate cognitive decline in the older adult populations according to our study results. Internet-based interventions or mealtime artificial intelligence partners might be useful in preventing cognitive decline in older adults.

Globally, home-delivered meals or congregate meal services have been provided to older adults at risk of malnutrition. Additionally, recent studies have emphasized nutritional programs that could provide both social interactions and nutritional benefits. ${ }^{23,24)}$ Further longitudinal studies or clinical trials are needed to demonstrate the effect of nutritional programs with social components for seniors on various health conditions, including cognitive function.

Our study had several limitations. First, because the 3-year period was relatively short to observe changes in cognitive function, the differences in MMSE-KC scores at baseline and follow-up among the four eating groups were relatively small. Second, we evaluated the nutritional risk using the NSI checklist. This screen- 
ing tool has been widely used in community research and has been validated in older adults at risk for malnutrition. ${ }^{25)}$ However, because it does not include accurate information on the food intake of the participants, we could not measure the precise dietary intake or quality. Further studies are needed to elucidate the role of these factors in cognitive function among older adults who eat alone. Despite these limitations, this study has several strengths. First, we used data from a nationwide representative sample of Korean older adults; therefore, our findings can be generalized. Second, previous Taiwanese and Japanese studies examined the combined effects of eating alone with nutritional status or living status on cognitive function. However, to our knowledge, this is the first prospective study to demonstrate that eating alone was independently associated with cognitive decline in older adults. Third, our findings remained significant after adjusting for a wide range of confounding factors.

In conclusion, the results of this study showed that the deprivation of mealtime partners in late life may aggravate cognitive decline in Korean older adults. Our findings suggest that the development of meal programs that reinforce social integration for seniors might contribute to preserving their cognitive function.

\section{ACKNOWLEDGMENTS}

\section{CONFLICT OF INTEREST}

The researchers claim no conflicts of interest.

\section{FUNDING}

This study was supported by the Korean Geriatrics Society Research Challenge Award (2019).

\section{AUTHOR CONTRIBUTION}

Conceptualization, HMN, YKR, JHH, HJS; Data curation, HMN, HJS; Supervision, YKR, HJS; Writing-original draft, HMN; Writing-review \& editing, YKR, HJS.

\section{REFERENCES}

1. Ferri CP, Prince M, Brayne C, Brodaty H, Fratiglioni L, Ganguli $\mathrm{M}$, et al. Global prevalence of dementia: a Delphi consensus study. Lancet 2005;366:2112-7.

2. Jang IY, Lee HY; Lee E; 50th Anniversary Committee of Korean Geriatrics Society. Geriatrics fact sheet in Korea 2018 from national statistics. Ann Geriatr Med Res 2019;23:50-3.

3. Petersson SD, Philippou E. Mediterranean diet, cognitive function, and dementia: a systematic review of the evidence. Adv Nutr 2016;7:889-904.
4. Taniguchi Y, Shinkai S, Nishi M, Murayama H, Nofuji Y, Yoshida $\mathrm{H}$, et al. Nutritional biomarkers and subsequent cognitive decline among community-dwelling older Japanese: a prospective study.J Gerontol A Biol Sci Med Sci 2014;69:1276-83.

5. Smyth A, Dehghan M, O'Donnell M, Anderson C, Teo K, Gao P, et al. Healthy eating and reduced risk of cognitive decline: a cohort from 40 countries. Neurology 2015;84:2258-65.

6. Sahyoun NR, Jacques PF, Dallal GE, Russell RM. Nutrition Screening Initiative Checklist may be a better awareness/educational tool than a screening one. J Am Diet Assoc 1997;97:7604.

7. Locher JL, Robinson CO, Roth DL, Ritchie CS, Burgio KL. The effect of the presence of others on caloric intake in homebound older adults. J Gerontol A Biol Sci Med Sci 2005;60:1475-8.

8. Tani Y, Kondo N, Takagi D, Saito M, Hikichi H, Ojima T, et al. Combined effects of eating alone and living alone on unhealthy dietary behaviors, obesity and underweight in older Japanese adults: Results of the JAGES. Appetite 2015;95:1-8.

9. Tsutsumimoto K, Doi T, Makizako H, Hotta R, Nakakubo S, Makino K, et al. Association of social frailty with both cognitive and physical deficits among older people. J Am Med Dir Assoc 2017;18:603-7.

10. Bennett DA, Schneider JA, Tang Y, Arnold SE, Wilson RS. The effect of social networks on the relation between Alzheimer's disease pathology and level of cognitive function in old people: a longitudinal cohort study. Lancet Neurol 2006;5:406-12.

11. Li CL, Tung HJ, Yeh MC. Combined effect of eating alone and a poor nutritional status on cognitive decline among older adults in Taiwan. Asia Pac J Clin Nutr 2018;27:686-94.

12. Suthutvoravut U, Tanaka T, Takahashi K, Akishita M, Lijima K. Living with family yet eating alone is associated with frailty in community-dwelling older adults: the Kashiwa study. J Frailty Aging 2019;8:198-204.

13. Park JI, Park TW, Yang JC, Chung SK. Factors associated with depression among elderly Koreans: the role of chronic illness, subjective health status, and cognitive impairment. Psychogeriatrics 2016;16:62-9.

14. Haskell WL, Lee IM, Pate RR, Powell KE, Blair SN, Franklin BA, et al. Physical activity and public health: updated recommendation for adults from the American College of Sports Medicine and the American Heart Association. Circulation 2007;116: 1081-93.

15. Bae JN, Cho MJ. Development of the Korean version of the Geriatric Depression Scale and its short form among elderly psychiatric patients.J Psychosom Res 2004;57:297-305.

16. Vesnaver E, Keller HH. Social influences and eating behavior in later life: a review. J Nutr Gerontol Geriatr 2011;30:2-23. 
17. Ybarra O, Winkielman P. On-line social interactions and executive functions. Front Hum Neurosci 2012;6:75.

18. Merrill N, Gallo E, Fivush R. Gender differences in family dinnertime conversations. Discourse Process 2015;52:533-58.

19. Kuiper JS, Zuidersma M, Oude Voshaar RC, Zuidema SU, van den Heuvel ER, Stolk RP, et al. Social relationships and risk of dementia: a systematic review and meta-analysis of longitudinal cohort studies. Ageing Res Rev 2015;22:39-57.

20. Makizako H, Tsutsumimoto K, Shimada H, Arai H. Social frailty among community-dwelling older adults: recommended assessments and Implications. Ann Geriatr Med Res 2018;22:3-8.

21. Bae S, Lee S, Lee S, Jung S, Makino K, Harada K, et al. The effect of a multicomponent intervention to promote community activity on cognitive function in older adults with mild cognitive impairment: a randomized controlled trial. Complement Ther
Med 2019;42:164-9.

22. Dodge HH, Zhu J, Mattek N, Bowman M, Ybarra O, Wild K, et al. Web-enabled conversational interactions as a means to improve cognitive functions: results of a 6-week randomized controlled trial. Alzheimers Dement (NY) 2015;1:1-12.

23. Thomas KS, Gadbois EA, Shield RR, Akobundu U, Morris AM, Dosa DM. "it's not just a simple meal. It's so much more": interactions between meals on wheels clients and drivers. J Appl Gerontol 2020;39:151-8.

24. Sheppard CL, Dube L, Ducak K, Myers AM. Development and evaluation of let's do lunch: a congregate meal program at an urban senior center. J Nutr Gerontol Geriatr 2018;37:49-58.

25. Posner BM, Jette AM, Smith KW, Miller DR. Nutrition and health risks in the elderly: the nutrition screening initiative. Am J Public Health 1993;83:972-8. 